\title{
Pengaruh Latihan Konvensional Terhadap Kemampuan Footwork Tenis Meja
}

\author{
Sefri Hardiansyah \\ Pendidikan Jasmani Kesehatan dan Rekreasi, Jurusan Pendidikan Olahraga, Fakultas Ilmu Keolahragaan, Universitas \\ Negeri Padang, Jalan Prof Dr. Hamka Air Tawar Barat, Padang 25132, Indonesia. \\ hardiansyah@fik.unp.ac.id
}

\begin{abstract}
ABSTRAK
Permasalahan dalam penelitian ini adalah masih kurangnya kemampuan footwork dalam bermain tenis meja mahasiswa UKO tenis meja UNP. Tujuan Penelitian ini adalah untuk mengetahui pengaruh latihan Konvensional terhadap kemampuan footwork. Penelitian ini termasuk penelitian eksperimen semu yang bertujuan untuk mengetahui pengaruh latihan konvensional terhadap kemampuan footwork mahasiswa UKO tenis meja UNP. Populasi dalam penelitian ini adalah mahasiswa UKO tenis meja UNP berjumlah 34 orang. Teknik pengambilan sampel menggunakan purposive sampling, sehingga jumlah sampel berjumlah 11 orang. Data dianalisis dengan menggunakan rumus uji t. Berdasarkan pengukuran dan analisa maka diperoleh hasil penelitian sebagai berikut: latihan konvensional memberikan pengaruh yang signifikan terhadap kemampuan footwork mahasiswa UKO tenis meja UNP.
\end{abstract}

kata kunci: latihan konvensional, footwork, tenis meja

\section{ABSTRACT}

The problem in this study is that there is still a lack of footwork ability in playing table tennis at UNP table tennis UKO students. The purpose of this study was to determine the effect of conventional training on footwork abilities. This research is a quasi-experimental study which aims to determine the effect of conventional training on the footwork ability of UNP table tennis UKO students. The population in this study were 34 UNP UKO table tennis students. The sampling technique uses proportional random sampling, so the number of samples is 22 people. Data were analyzed using t test formula. Based on measurements and analysis, the results of the study are as follows: conventional training has a significant influence on the ability of footwork of UNP table tennis UKO students.

Key words: conventional training, footwork, table tennis

\section{PENDAHULUAN}

Unit Kegiatan Olahraga (UKO) merupakan salah satu wadah yang menyelenggarakan pelaksanaan proses kegiatan olahraga yang berada di lingkungan universitas, salah satunya Unit Kegiatan Olahraga (UKO) Tenis Meja di Universitas Negeri Padang. Berdasarkan pengamatan dan wawancara penulis dengan beberapa orang anggota dan pelatih yang berada di Unit Kegiatan Olahraga (UKO), penulis memperoleh informasi bahwa pelaksanaan proses kegiatan olahraga berjalan dengan maksimal ini dibuktikan dengan masih banyak anggota yang memiliki kesulitan dalam melakukan perpindahan gerak langkah kaki (footwork), sehingga tidak bisa melakukan pukulan dan gerakan dengan leluasa. Pelaksanaan unit kegiatan olahraga tenis meja dapat dipengaruhi oleh beberapa faktor diantaranya adalah kondisi fisik, teknik, sarana dan prasarana, pelatih, motivasi, serta pengalaman.

Berdasarkan uraian di atas, maka penulis tertarik untuk mengadakan penelitian yang berkaitan dengan masalah tersebut di atas. Dari penelitian ini penulis berharap bisa membantu memberi solusi terhadap masalah footwork (kerja 
kaki) yang dialami oleh anggota Unit Kegiatan Olahraga (UKO) Tenis Meja di Universitas Negeri Padang.

\section{Tenis Meja}

Hodges (1996:1) mengemukakan "Tenis meja adalah permainan dimana sebuah bola kecil yang putih dipukul bolak-balik hingga seseorang melakukan kesalahan". Menerapkan koordinasi seluruh komponen fisik juga terdapat dalam tenis meja. Dengan ide mematikan bola didaerah lawan sehingga menghasilkan poin dan memperoleh kemenangan. Permainan dengan individu yaitu permainan yang dimainkan seorang atau tunggal, sedangkan kelompok yaitu permainan yang dimainkan dengan ganda maupun beregu. Dalam tenis meja ada istilah single/ tunggal dan double/ganda. Permainan single dimainkan oleh satu lawan satu, sedangkan permainan double dimainkan dua lawan dua dengan aturan yang telah ditetapkan.

Permainan tenis meja menggunakan beberapa peralatan antara lain ; meja, net, bola dan bet. Kalau mental sudah terlatih, maka teknik yang dipelajari akan bisa diimplementasikan dengan baik. Makanya antara kondisi fisik, teknik, taktik dan mental saling keterkaitan dalam tenis meja untuk memperoleh kemenangan.

\section{Footwork (kerja kaki)}

Istilah footwork (kerja kaki) sering didengar dalam beberapa cabang olahraga. Kemampuan footwork (kerja kaki) mempunyai peranan penting dalam permainan tenis meja karena laju bola yang sangat cepat dibutuhkan gerak kaki yang cepat dan tepat pula. Damiri (1992:110), "Footwork (kerja kaki) dalam permainan tenis meja pada garis besarnya dapat dibedakan untuk nomor tunggal atau nomor ganda" Seorang pemain harus memperhitungkan kecepatan serta arah putaran bola. Pemain harus segera mengambil keputusan dengan cepat dan tepat agar mendapatkan keuntungan yang besar, tentu saja dapat mempermudah dalam meraih kemenangan dalam suatu pertandingan.

Permainan tenis meja bukan hanya masalah tangan saja, dari perkembangan teknik dapat dipahami untuk mencapai posisi yang maksimal harus ditunjang dengan sistem gerak langkah kaki yang makin sempurna, sehingga upaya untuk merebut kesempatan menyerang. Dalam permainan tenis meja kemampuan koordinasi mempunyai peranan penting untuk dalam pembelajaran bagi para pemain tenis meja tingkat pemula sehingga dapat memukul bola secara akurat disertai dengan gerakan kaki yang tepat.

\section{Latihan konvensional}

Menurut Cholik (2000: 58) latihan dalam konteks olahraga adalah "aktivitas yang dilakukan secara sistematis, terencana, berulang, dan meningkat dengan cara bertahap dalam waktu yang lama, yang bertujuan meningkatkan fungsi fisiologis, psikologis dan sosiologis pelakunya guna memenuhi kebutuhan tugasnya". Sedangkan menurut Iriyanto dalam Yuliawan (2014) latihan adalah proses pelatihan dilaksanakan secara teratur, terencana, menggunakan pola dan sistem tertentu, metodis serta berulang seperti gerakan yang semula sukar dilakukan, kurang koordinatif menjadi semakin mudah, otomatis, dan reflektif sehingga gerak menjadi efisien dan itu harus dikerjakan berkali-kali. Djamarah (1996), metode pembelajaran konvensional adalah metode pembelajaran tradisional atau disebut juga dengan metode ceramah, karena sejak dulu metode ini telah dipergunakan sebagai alat komunikasi lisan antara guru dengan anak didik dalam proses belajar dan pembelajaran.

Pelatih dalam metode konvensional biasanya menyampaikan materi dalam bentuk ceramah atau penjelasan lisan, peserta diharapkan dapat mengungkapkan kembali semua yang telah dimiliki ketika diberi pertanyaan oleh pelatih. Komunikasi yang digunakan adalah searah, kegiatan peserta terbatas pada ucapan pelatih, mencatat dan sesekali bertanya. Latihan konvensional lebih berpusat pada guru (teacher centered). Jika dikaitkan ke lingkungan olahraga, maka pembelajaran akan terpusat pada pelatih. Kegiatan pembelajaran yang berpusat pada pelatih menekankan pentingnya aktivitas pelatih dalam membelajarkan peserta. Peserta berperan sebagai pengikut dan penerima pasif dari kegiatan yang dilaksanakan.

\section{METODE PENELITIAN}

Dalam penelitian ini metode yang digunakan adalah penelitian eksperimen semu. Penelitian ini bertujuan untuk mengetahui pengaruh latihan konvensional terhadap footwork mahasiswa Unit 
kegiatan Olahraga Tenis Meja UNP. Populasi terdiri dari 34 orang, teknik penarikan sampel menggunakan purposive sampling yaitu hanya atlet yang mengikuti latihan $<6$ bulan yang berjumlah 11 orang. Instrument penelitian adalah adalah unjuk kerja footwork yang diukur menggunakan langkah ke arah 8 penjuru mata angin, dengan reliabilitas tes 0.982 dan validitas 0,961 . Hasil yang dicatat adalah jumlah skor yang diperoleh testi selama 30 detik. data dianalisis menggunakan uji $\mathrm{t}$ dependent sampel. Sebelumnya terlebih dahulu dilakukan uji persyaratan analisis menggunakan uji normalitas.

\section{HASIL PENELITIAN}

\section{Deskripsi Data}

Pada bagian ini akan sajikan deskripsi data footwork yang merupakan hasil pengukuran awal terhadap seluruh objek penelitian. Berdasarkan rancangan penelitian eksperimen yang dilakukan, ada satu kelompok data yang akan dideskripsikan secara terpisah. Berikut ini disajikan deskripsi data footwork.

\section{a. Pre test}

Dari hasil pengukuran footwork yang dilakukan terhadap sampel mahasiswa UKO Tenis Meja UNP diperoleh skor tertinggi 20, skor terendah 15. Berdasarkan kelompok data footwork menggunakan metode konvensional diperoleh nilai rata-rata hitung (mean) 16.82, nilai tengah (median) 16, dan simpangan baku (standard deviasi) sebesar 1.72. Untuk lebih jelasnya distribusi data footwork ini dapat dilihat pada tabel di bawah ini.

Tabel 1. Distribusi Frekwensi Data Pre Test

\begin{tabular}{|c|c|c|c|}
\hline Klasifikasi & $\begin{array}{c}\text { Kelas } \\
\text { Interval }\end{array}$ & Fa & Fr\% \\
\hline Baik Sekali & $>19.40$ & 1 & 9.09 \\
\hline Baik & $17.68-19.39$ & 3 & 27.27 \\
\hline Sedang & $15.96-17.65$ & 4 & 36.36 \\
\hline Kurang & $14.24-15.95$ & 3 & 27.27 \\
\hline Kurang Sekali & $<14.23$ & 0 & 0 \\
\hline \multicolumn{2}{|c|}{ Jumlah } & 11 & 100 \\
\hline
\end{tabular}

Berdasarkan tabel frekwensi di atas dari 11 orang mahasiswa, ternyata sebanyak 1 orang mahasiswa (9.09\%) memiliki Footwork dengan kelas interval berkisar dari $>19.40$ dengan kategori baik sekali, kemudian sebanyak 3 orang mahasiswa (27.27\%) memiliki Footwork dengan kelas interval berkisar dari 17.68-19.39 dengan kategori baik, lalu sebanyak 4 orang mahasiswa (36.36\%) memiliki Footwork dengan kelas interval berkisar dari 15.96-17.65 dengan kategori sedang, sedangkan sebanyak 3 orang mahasiswa (27.27\%) memiliki Footwork dengan kelas interval berkisar dari 14.24-15.95 dengan kategori kurang dan sebanyak 0 orang mahasiswa $(0 \%)$ memiliki Footwork dengan kelas interval berkisar dari < 14.23 dengan kategori kurang sekali. Data tersebut kemudian disajikan ke dalam diagram lingkaran sebagai berikut:

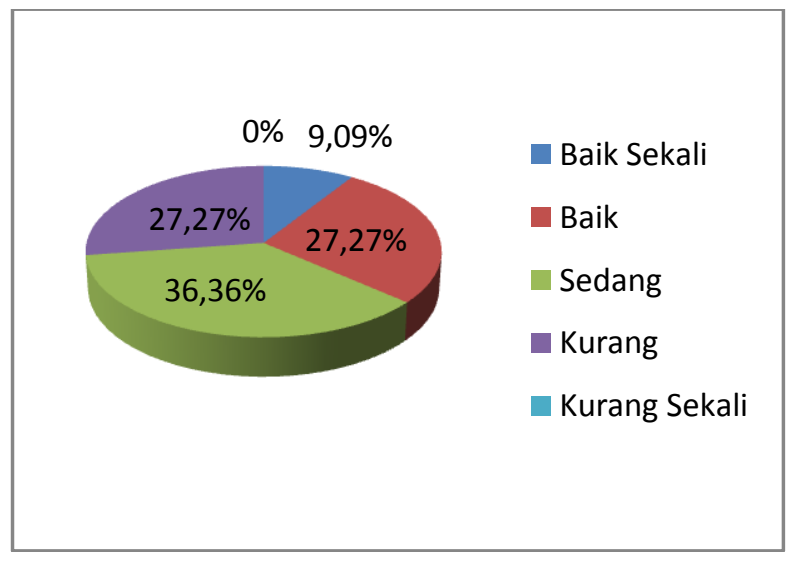

Grafik 1. Data Pre Test

\section{b. Post test}

Dari hasil pengukuran footwork yang dilakukan terhadap sampel mahasiswa UKO Tenis Meja UNP diperoleh skor tertinggi 22, skor terendah 16. Berdasarkan kelompok data footwork menggunakan metode konvensional diperoleh nilai rata-rata hitung (mean) 18.91, nilai tengah (median) 19, dan simpangan baku (standard deviasi) sebesar 2.12. Untuk lebih jelasnya distribusi data footwork ini dapat dilihat pada tabel di bawah ini.

Tabel 2. Distribusi Frekwensi Data Post Test

\begin{tabular}{|c|c|c|c|}
\hline Klasifikasi & $\begin{array}{c}\text { Kelas } \\
\text { Interval }\end{array}$ & Fa & Fr\% \\
\hline Baik Sekali & $>22.09$ & 0 & 0 \\
\hline Baik & $19.97-22.08$ & 4 & 36.36 \\
\hline Sedang & $17.85-19.96$ & 4 & 36.36 \\
\hline Kurang & $15.73-17.84$ & 3 & 27.27 \\
\hline Kurang Sekali & $<15.72$ & 0 & 0 \\
\hline \multicolumn{2}{|c|}{ Jumlah } & 11 & 100 \\
\hline
\end{tabular}


Berdasarkan tabel frekwensi di atas dari 11 orang mahasiswa, ternyata tidak ada mahasiswa (0\%) memiliki Footwork dengan kelas interval berkisar dari >22.09 dengan kategori baik sekali, kemudian sebanyak 4 orang mahasiswa (36.36\%) memiliki Footwork dengan kelas interval berkisar dari 19.97-22.08 dengan kategori baik, lalu sebanyak 4 orang mahasiswa $(36.36 \%)$ memiliki Footwork dengan kelas interval berkisar dari 17.85-19.96 dengan kategori sedang, sedangkan sebanyak 3 orang mahasiswa $(27.27 \%)$ memiliki Footwork dengan kelas interval berkisar dari 15.73-17.84 dengan kategori kurang dan sebanyak 0 orang mahasiswa $(0 \%)$ memiliki Footwork dengan kelas interval berkisar dari $<15.72$ dengan kategori kurang sekali. Data akhir tersebut kemudian disajikan ke dalam diagram lingkaran sebagai berikut:

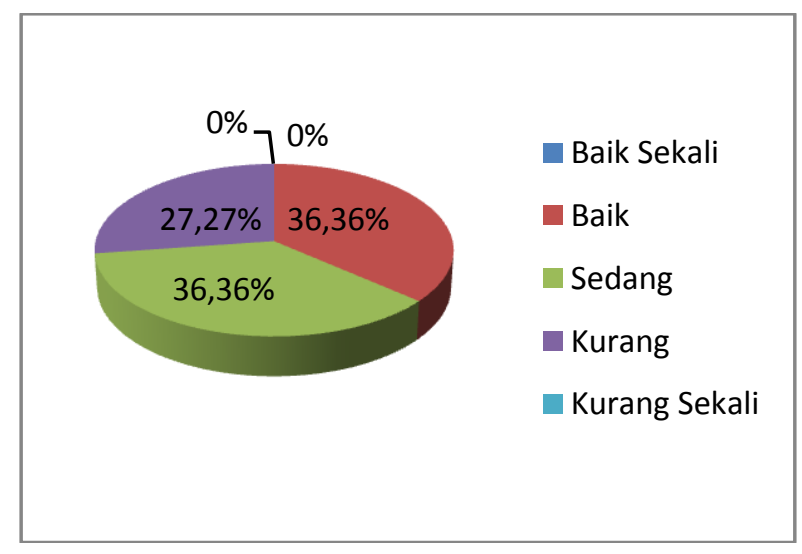

Grafik 2. Data Post Test

Berdasarkan deskripsi data awal dan data akhir di atas, dapat dinyatakan bahwa terjadi peningkatan rata-rata kemampuan footwork mahasiswa UKO Tenis Meja UNP sebesar 2.09. Dimana rata-rata data awal 16.82 menjadi 18.91 pada data akhir setelah diberi perlakuan secara konvensional.

\section{Pengujian Persyaratan Analisis Uji Normalitas}

Data variabel yang diteliti berdistribusi normal digunakan uji Liliefors. Hasil perhitungan lengkap uji normalitas dapat dilihat pada tabel berikut:
Tabel 3. Rangkuman Hasil Uji Normalitas Data Latihan menggunakan video dan Konvensional

\begin{tabular}{|c|c|c|c|c|c|}
\hline Latihan & Data & $\mathbf{N}$ & $\mathbf{L}_{\mathbf{0}}$ & $\mathbf{L t}$ & Ket \\
\hline \multirow{2}{*}{ Konvensional } & $\begin{array}{c}\text { Pre } \\
\text { Test }\end{array}$ & 11 & 0,2282 & 0.2490 & Normal \\
\cline { 2 - 6 } & $\begin{array}{c}\text { Post } \\
\text { Test }\end{array}$ & 11 & 0,1206 & 0.2490 & Normal \\
\hline
\end{tabular}

\section{Pengujian Hipotesis}

Hipotesis yang diajukan dalam penelitian ini yaitu terdapat pengaruh yang signifikan oleh latihan konvensional memberikan pengaruh terhadap kemampuan footwork tenis meja. Berdasarkan analisis yang dilakukan, maka didapat rata-rata data awal (pre test) latihan konvensional sebesar 16.82, dan rata-rata data akhir (post tes) sebesar 18.91. Berdasarkan uji beda (uji t) dependent sampel yang dilakukan maka diperoleh $t_{\text {hitung }}$ sebesar 3.94 dan $\mathrm{t}_{\text {tabel }}$ pada alfa 0.05 dan $\mathrm{dk}=\mathrm{n}-1$ adalah sebesar 2.228 , $t_{\text {hitung }} 3.94>t_{\text {tabel }} 2.228$ dengan demikian maka $\mathrm{H}_{0}$ ditolak dan Ha diterima dengan kata lain bahwa hipotesis pertama dalam penelitian ini diterima kebenarannya secara empiris.

Tabel 4. Hasil Pengujian Hipotesis

\begin{tabular}{|c|c|c|c|c|c|}
\hline Kelompok & Mean & $\mathbf{t}_{\text {hitung }}$ & $\mathbf{d k}$ & $\mathbf{t}_{\text {tabel }}$ & Ket \\
\hline Pre Test & 16.82 & \multirow{2}{*}{3.94} & $\mathrm{n}-1$ & 2.228 & $\begin{array}{c}\text { Berbeda } \\
\text { Signifikan }\end{array}$ \\
\hline Post Test & 18.91 & & &
\end{tabular}

\section{PEMBAHASAN}

Menurut Trianto, (2007:41) metode konvensional merupakan penyajian informasi yang akan dipelajari dengan cara memberikan contoh, mencoba dan mengerti apa yang disampaikan oleh guru/pelatih. Pelatih dalam metode konvensional biasanya menyampaikan materi dalam bentuk ceramah atau penjelasan lisan, peserta diharapkan dapat mengungkapkan kembali semua yang telah dimiliki ketika diberi pertanyaan oleh pelatih. Komunikasi yang digunakan adalah searah, kegiatan peserta terbatas pada ucapan pelatih, mencatat dan sesekali bertanya. Latihan konvensional lebih berpusat pada guru (teacher centered). Jika dikaitkan ke lingkungan olahraga, maka pembelajaran akan terpusat pada pelatih. Kegiatan pembelajaran yang berpusat pada pelatih menekankan pentingnya aktivitas pelatih dalam 
membelajarkan peserta. Peserta berperan sebagai pengikut dan penerima pasif dari kegiatan yang dilaksanakan.

Hasil pengujian hipotesis kedua menunjukkan bahwa $t_{\text {hitung }}$ sebesar 3,94 sedangkan $t_{\text {tabel }}$ pada $\alpha 0.05$ sebesar 2,23. Jadi $t_{\text {hitung }} 3,94>$ $t_{\text {tabel }} 2,23$. Jadi dapat disimpulkan bahwa terdapat pengaruh yang signifikan oleh latihan konvensional terhadap kemampuan footwork tenis meja dapat diterima kebenarannya secara empiris. Latihan konvensional dapat meningkatkan kemampuan footwork mahasiswa UKO tenis meja UNP.

Berdasarkan temuan penelitian maka dapat dibuktikan bahwa atlet yang baru bergabung membutuhkan contoh terlebih dahulu sebelum dapat melakukan gerakan footwork. Gerakan footwork merupakan pola langkah yang harus dilakukan atlet dengan benar agar atlet dapat bermain dengan baik dan maksimal. Kesalahan dalam melakukan kegiatan footwork dapat mengakibatkan.

\section{KESIMPULAN}

Berdasarkan hasil penelitian maka dapat disimpulkan sebagai berikut: Latihan konvensional memberikan pengaruh signifikan terhadap kemampuan footwork mahasiswa UKO tenis meja UNP.

\section{DAFTAR PUSTAKA}

Cholik Mutohir Toho. 2000. Penelitian Aksi Dalam Proses Pelatihan Olahraga. KONI : UNS

Damiri, Ahmad dkk. 1991. Olahraga Pilihan Tenis Meja. Bandung: Depdikbud.

Djamarah, Syaiful Bahri. 2010. Stategi Belajar Mengajar. Jakarta: Rineka Cipta.

Hodges, Larry. 1996. Tenis Meja Tingkat Pemula. Jakarta: Raja Grafindo Persada.

Trianto. 2007. Model-Model Pembelajaran Inovatif Berorientasi Konstruktifistik. Jakarta: Prestasi Pustaka Publisher.

Yuliawan Dhedhy, FX Sugiyanto. 2014. Pengaruh metode latihan pukulan dan kelincahan terhadap keterampilan bermain bulutangkis atlet tingkat pemula. Jurnal: Ilmu Keolahragaan, Volume 2 No 2, 145-154. 